\title{
Diversity and community structure of marine microbes around the Benham Rise underwater plateau, northeastern Philippines
}

\author{
Andrian P. Gajigan ${ }^{1}$, Aletta T. Yñiguez ${ }^{1}$, Cesar L. Villanoy ${ }^{1}{ }^{\text {, }}$ Maria Lourdes San Diego-McGlone ${ }^{1}$, Gil S. \\ Jacinto $^{1}$, Cecilia Conaco ${ }^{\text {Corresp. } 1}$ \\ ${ }^{1}$ Marine Science Institute, University of the Philippines Diliman, Quezon City, Philippines \\ Corresponding Author: Cecilia Conaco \\ Email address: cconaco@msi.upd.edu.ph
}

Microbes are central to the structuring and functioning of marine ecosystems. Given the remarkable diversity of the ocean microbiome, uncovering marine microbial taxa remains a fundamental challenge in microbial ecology. However, there has been little effort, thus far, to describe the diversity of marine microorganisms in the region of high marine biodiversity around the Philippines. Here we present data on the taxonomic diversity of bacteria and archaea in Benham Rise, Philippines, Western Pacific Ocean, using 16S V4 rRNA gene sequencing. The major bacterial and archaeal phyla identified in the Benham Rise are Proteobacteria, Cyanobacteria, Actinobacteria, Bacteroidetes, Marinimicrobia, Thaumarchaeota and, Euryarchaeota. The upper mesopelagic layer exhibited greater microbial diversity and richness compared to surface waters. Vertical zonation of the microbial community is evident and may be attributed to physical stratification of the water column acting as a dispersal barrier. Canonical Correspondence Analysis (CCA) recapitulated previously known associations of taxa and physicochemical parameters in the environment, such as the association of oligotrophic clades with low nutrient surface water and deep water clades that have the capacity to oxidize ammonia or nitrite at the upper mesopelagic layer. These findings provide foundational information on the diversity of marine microbes in Philippine waters. Further studies are warranted to gain a more comprehensive picture of microbial diversity within the region. 
1 Diversity and community structure of marine microbes around the Benham Rise underwater

2 plateau, northeastern Philippines

3 Andrian P. Gajigan ${ }^{\dagger}$, Aletta T. Yñiguez, Cesar L. Villanoy, Maria Lourdes San Diego-McGlone,

4 Gil S. Jacinto, and Cecilia Conaco*

5

6 Marine Science Institute, University of the Philippines Diliman, Quezon City, 1101, Philippines

7 †ew address: Department of Oceanography, University of Hawaii at Manoa, USA

8

$9 *$ Corresponding author:

10 Cecilia Conaco

11 Marine Science Institute

12 University of the Philippines Diliman

13 E-mail: cconaco@msi.upd.edu.ph

14

15

16

17

18

19

20

21

22

23 


\section{Abstract}

25

26 Microbes are central to the structuring and functioning of marine ecosystems. Given the 27 remarkable diversity of the ocean microbiome, uncovering marine microbial taxa remains a 28 fundamental challenge in microbial ecology. However, there has been little effort, thus far, to 29 describe the diversity of marine microorganisms in the region of high marine biodiversity around 30 the Philippines. Here we present data on the taxonomic diversity of bacteria and archaea in Benham 31 Rise, Philippines, Western Pacific Ocean, using 16S V4 rRNA gene sequencing. The major 32 bacterial and archaeal phyla identified in the Benham Rise are Proteobacteria, Cyanobacteria, 33 Actinobacteria, Bacteroidetes, Marinimicrobia, Thaumarchaeota and, Euryarchaeota. The upper 34 mesopelagic layer exhibited greater microbial diversity and richness compared to surface waters. 35 Vertical zonation of the microbial community is evident and may be attributed to physical 36 stratification of the water column acting as a dispersal barrier. Canonical Correspondence Analysis 37 (CCA) recapitulated previously known associations of taxa and physicochemical parameters in the 38 environment, such as the association of oligotrophic clades with low nutrient surface water and 39 deep water clades that have the capacity to oxidize ammonia or nitrite at the upper mesopelagic layer. These findings provide foundational information on the diversity of marine microbes in

41 Philippine waters. Further studies are warranted to gain a more comprehensive picture of microbial 42 diversity within the region. 


\section{Introduction}

48

49 Microbes play a critical role in marine ecosystem structure and ocean biogeochemistry. Thus, it

50 remains essential to understand the vast diversity of microbes living in our seas. Efforts to explore

51 areas that harbor the greatest biodiversity, such as aquatic environments, are needed to capture

52 microorganisms that are rarer and less abundant (Schloss et al. 2016). Traditionally, classification

53 of microorganisms required that they be grown in pure culture. However, difficulties in mimicking

54 specific environmental conditions that many marine bacteria require to grow in isolation have been

55 a major impediment. The advancement of next-generation sequencing technologies has

56 circumvented these challenges by allowing microbial community profiles to be directly obtained

57 from environmental samples using the 16S rRNA gene as a barcode.

58

59 Understanding the biodiversity and the types of microbes that are present in a community is

60 important as it provides information on ecosystem functioning (Loreau et al. 2001). The

61 remarkable diversity of marine microbes can be attributed to their early evolution, rapid generation

62 time, and the heterogeneity of the micro-environment (Staley 2006). The heterogeneity of the

63 ocean due to the presence of nutrient patches and microscale gradients (Stocker 2012) results in

64 different niches that can support diverse types of microbes (i.e., niche exclusion principle; Kassen

$65 \&$ Rainey, 2004). In addition to these small-scale differences, large-scale spatial and temporal

66 variations in the ocean also contribute to environmental heterogeneity and can sustain diversity

67 (Kassen \& Rainey 2004). Other factors that may drive microbial diversity include dispersal,

68 recombination, and coevolution through the processes of symbiosis and competition (Kassen \&

69 Rainey 2004). 
70 The archipelagic topology of the Philippines coupled with the range of geologic and oceanographic

71 regimes (i.e., upwelling systems, anoxic basins, eutrophic coastal areas, and tectonically active

72 regions, among others) provide diverse environments that may support biodiversity. Philippine

73 waters host a diverse community of marine fishes, invertebrates, plants and zooplankton

74 (Carpenter \& Springer 2005; Tittensor et al. 2010), with which microorganisms may coevolve.

75 Attributes such as habitat availability, heterogeneity, and sea surface temperature are said to be

76 highly correlated with high species richness in the Philippines and nearby regions (Sanciangco et

77 al. 2013). For these reasons, the waters surrounding the Philippine archipelago are likely to be 78 areas of high microbial diversity.

79

80 The Benham Rise (also known as Philippine Rise) is an underwater plateau situated northeast of

81 the Philippines, Western Pacific Ocean, where a convergence of waters occurs. Surface currents

82 are mainly from North Pacific subtropical waters and Kuroshio recirculated waters, with inputs

83 from the North Equatorial current, as well. These areas are vital to global ocean circulation and

84 climate (Gordon et al. 2014; Hu et al. 2015). However, marine microbial taxa in the Western

85 Pacific region are largely uncharted. These waters have not yet been explored by global efforts to 86 sample the ocean microbiome, such as the Global Ocean Sampling (GOS) and Tara Expeditions

87 (Parthasarathy et al. 2007; Sunagawa et al. 2015). This study thus provides foundational data on

88 the microbial diversity of the Benham Rise and reveals the association of microbial community 89 structure with environmental factors. 


\section{Materials and Methods}

94

95

Physical and chemical measurements

96 Water samples were collected at different depths for physicochemical measurements focusing on

97 the surface (SURF; 10m), deep chlorophyll-a maximum (DCM; $\sim 90-210 \mathrm{~m}$ ), and upper 98 mesopelagic layer (UMP; 300m) using Niskin bottles mounted on a rosette on board M/V DA 99 BFAR on May 3-18, 2014 at Benham Rise (BR, Figure 1). Nitrite, nitrate, silicate, and phosphate 100 measurements were determined spectrophotometrically following standard protocols (Strickland 101 \& Parsons 1972) using a Skalar Sans++ segmented flow analyzer D5000. Water samples for 102 carbonate measurements were preserved using mercuric chloride and analyzed using a Kimoto 103 total alkalinity titrator. Depth-profiles of conductivity, temperature, depth, dissolved oxygen (DO), 104 and chlorophyll- $a$ were determined using a Seabird ${ }^{\text {TM }}$ SBE 19 plus attached to the rosette frame.

\section{On-board microbial sampling}

107 Three depths were sampled for microbial analysis (SURF, DCM, and UMP) for 5 stations. Water 108 samples were collected from Niskin samplers into autoclaved bottles. Approximately $1 \mathrm{~L}$ of water was pre-filtered through a sterile $20 \mu \mathrm{m}$ mesh before filtering through a $0.2 \mu \mathrm{m}$ polycarbonate

110 filter. The size fraction collected captures both free-living and particle-attached microbes. The 111 filter units were then placed in DNA lysis buffer (40 mM EDTA, 0.7 M sucrose, and $50 \mathrm{mM}$ 112 TrisCl) and frozen at $-80^{\circ} \mathrm{C}$ until extraction. 
DNA extraction

117 DNA was extracted using standard methods employing both enzymatic and bead beating

118 homogenization (de Boer et al. 2010; Huber et al. 2002). Lysis and cell wall digestion were done

119 with the addition of $40 \mu \mathrm{l}$ of $50 \mathrm{mg} / \mathrm{ml}$ of lysozyme to thawed sample. Bead beating was carried 120 out using ZR BashingBeads ${ }^{\mathrm{TM}}$ in a Precellys ${ }^{\circledR}$ homogenizer at $5000 \mathrm{rpm}$ for $3 \times 60$ seconds. Then,

121 samples were incubated at $37^{\circ} \mathrm{C}$ for 1 hour. Further digestion was carried out by adding $50 \mu l$ of $12220 \mathrm{mg} / \mathrm{ml}$ proteinase $\mathrm{K}$ and $100 \mu \mathrm{l}$ of $20 \%$ SDS (sodium dodecyl sulfate) and incubation for 2

123 hours at $55^{\circ} \mathrm{C}$. Organic extraction was done using phenol-chloroform-isoamyl alcohol (25:24:1)

124 and subsequently with chloroform-isoamyl alcohol (24:1). DNA was precipitated with an equal

125 volume of isopropanol, washed with $70 \%$ ethanol, and resuspended in nuclease-free water.

126

127 16S rRNA amplification and sequencing

128 The V4 region of the 16S rRNA gene was amplified from the extracted genomic DNA using 129 primers, 515F (5'-GTGCCAGCMGCCGCGGTAA-3') and $\quad 806 \mathrm{R} \quad\left(5^{\prime}-\right.$ 130 GGACTACHVGGGTWTCTAAT-3') as previously described (Caporaso et al. 2012). Paired-end 131 sequencing (250 bp) was performed on the Illumina MiSeq platform (Beijing Genomic Institute, 132 Hong Kong) with an output of approximately 50,000-100,000 reads per sample. Raw sequencing 133 reads are available on NCBI as BioProject number PRJNA386402.

134

135 I6S rRNA sequence analysis

136 Assembly of paired-end reads into contigs and quality filtering were implemented following the 137 mothur MiSeq pipeline (v1.35.1) (Kozich et al. 2013; Schloss et al. 2009). Assembled contigs were 138 aligned to the SILVA version 132 database (Quast et al. 2013). Reads were checked for chimeric 
139 sequences using the Uchime algorithm (Edgar et al. 2011). Sequences with $>97 \%$ rDNA sequence

140 similarity were clustered into operational taxonomic units (OTU). OTUs were taxonomically

141 classified using the SILVA version 132 database. Diversity, richness, and community comparisons

142 were also calculated using mothur. Statistical tests, including (1) Parsimony test, (2) weighted and

143 unweighted Unifrac, (3) AMOVA, (4) HOMOVA and (5) J-LIBSHUFF were implemented in

144 mothur to test whether microbial communities across depths have similar structure (Schloss 2008).

145 LEfSe (Segata et al. 2011) and indicator analysis (Dufrêne \& Legendre 1997) were implemented

146 in mothur to identify overrepresented OTUs.

147

148 Integrating physicochemical and $16 S$ rRNA sequence data

149 Canonical correspondence analysis (Ter Braak 1986) was implemented in XLSTAT to explain the

150 variation in microbial communities, specifically to relate species abundance to environmental

151 condition. The relative abundance of major taxa were square-root transformed for normalization

152 while variables, such as nitrite+nitrate, phosphate, silicate, and chlorophyll-a concentration, were

$153 \log (\mathrm{x}+1)$ transformed (Ramette 2007). Samples with undetectable concentrations of phosphate and

154 nitrite+nitrate were set to zero before transformation. Variables such as temperature, salinity, DO, $155 \mathrm{pH}$, and turbidity were not data transformed.

156

157 Results

158

159 Oceanography of Benham Rise

160 Benham Rise, bounded by the coordinates $119^{\circ} 30^{\prime} \mathrm{E}$ to $132^{\circ} 00^{\prime} \mathrm{E}$ longitude and $12^{\circ} 10^{\prime} \mathrm{N}$ to $16120^{\circ} 30^{\prime} \mathrm{N}$ latitude, is an underwater inactive volcano (Philippines 2009; Savov 2005). It is a plateau, 
162 which stands $3500 \mathrm{~m}$ and $500 \mathrm{~m}$ above the surrounding seafloor at its crest, and northern-eastern

163 margins, respectively. Oceanographic measurements and bacterial sampling were done around

164 Benham Bank ( $\sim 50$ meters deep), the shallowest portion of Benham Rise. Twenty-four stations

165 were occupied around Benham Bank for physicochemical measurements, five stations were also

166 sampled for microbial community analysis (Figure 1 and Table S1). In total, 5 surface (SURF), 4

167 deep-chlorophyll maximum (DCM), and 2 upper mesopelagic (UMP) samples were obtained.

168 Stratification of physical and chemical properties is evident in the water column. A strong gradient

169 in temperature and salinity were found at the upper 20-40m and at 200-400m (Figure S1A, S1B

170 and Table S2). Deep chlorophyll maximum was detected at around 110 to $150 \mathrm{~m}$ (Figure S1C)

171 while oxygen minima were detected at $200 \mathrm{~m}$ and at $750 \mathrm{~m}$ (Figure S1D). Nutrient concentration

172 increased with depth as expected for a stratified, oligotrophic ocean, while $\mathrm{pH}$ decreased with 173 depth (Figure S2 and Table S3).

174

175

\section{Microbial community composition and structure}

176 A total of 837,124 reads were pooled from 11 samples. Removal of contigs with ambiguous bases

177 and reads with length $>275$ resulted in the rejection of $25 \%$ of the initial reads. Elimination of

178 chimaeras and removal of lineages corresponding to chloroplast, eukaryotes, mitochondria, and

179 unknown sequences, resulted in the removal of $21.7 \%$ and $1.4 \%$ of the contigs, respectively. After

180 quality filtering steps, 483,773 contigs corresponding to 37,659 unique sequences remained. These

181 sequences were classified into 10,599 OTUs (4,887 OTUs without singletons). The non-plateauing

182 rarefaction curves suggest that Benham Rise waters host a much more diverse prokaryotic

183 community than reported here (Figure S3). There is also an increasing trend in indices of species

184 richness and diversity with increasing depth (Figure 2). 
185 Samples from the same depth taken at different stations exhibited more similar community 186 composition than samples from different depths taken at the same stations (Figure 3A). Only 441

187 OTUs were common to all depths (Figure 3B). 2,980 OTUs were specific to the surface samples, 188 3,791 to the DCM, and 1,837 to the UMP. More OTUs overlapped between surface and DCM 189 (789) and between DCM and UMP (692) compared to surface and UMP (69). Significant 190 differences in microbial community structure across depths were supported by weighted UniFrac 191 and AMOVA $(\mathrm{p}<0.05)$ but not by unweighted UniFrac $(\mathrm{p}<0.05)$, and HOMOVA $(\mathrm{p}>0.05)($ Table 192 S4). Only the surface and DCM communities were significantly different under the Parsimony test $193(\mathrm{p}<0.05)$ and $\int$-LIBSHUFF $(\mathrm{p}<0.025$ for two $\mathrm{p}$-values) using Jaccard distances as input (Table 194 S4).

195

196 The 10 most dominant bacterial phyla detected in the Benham Rise water column were 197 Proteobacteria, Cyanobacteria, Actinobacteria, Bacteroidetes, Marinimicrobia, Chloroflexi, 198 Planctomycetes, Verrucomicrobia, Acidobacteria, and Nitrospinae, while Thaumarchaeota and 199 Euryarchaeota were the major archaeal phyla (Figure 3C). Cyanobacteria constituted a major 200 proportion of surface and DCM sequences, with $16 \%-43 \%$ of sequences belonging to 201 Prochlorococcus and 0.1\%-9.31\% to Synechococcus. Other ecologically relevant marine taxa that 202 were detected at all sampled depths were SAR 11 (0.05\%-1.45\%), SAR86 (0.9\%-8\%), SAR116 $203(0.01 \%-4 \%)$, SAR406 (Marine Group A) (0.5\%-8.7\%), SAR324 (Marine Group B) (0.05\%-4.7\%), 204 and Alteromonas (0.15\%-16\%). SAR202 (4\%) and archaeal groups, including Nitrosopumilaceae 205 (21\%-48\%), a family within Marine Group I (Konneke et al. 2005), as well as Marine Group II (2206 3\%), Marine Group III (1\%), and Candidatus Nitrosopelagicus (4\%-7\%), were abundant in the 207 UMP layer. Some OTUs were significantly overrepresented at different depths, notably Otu00007 
208 (SAR86) and Otu00015 (SAR116) in the surface, Otu00009 (Marine Group II) in the DCM, and 209 Otu00005 (Nitrosopumilaceae) in the UMP (Table S5). Indicator analysis revealed OTUs that are 210 responsible for differences in groupings of samples, including Otu00310 (Spirochaeta) and 211 Otu00702 (Nitrospina) for UMP (Table S5).

212

213 Physicochemical parameters affecting microbial species abundance

214 CCA showed association of major phyla with physicochemical properties of the water column 215 (Figure 4). Samples from the same depth grouped together in CCA ordination, which agreed with 216 the depth-related distribution patterns revealed by Jaccard index, weighted UniFrac, and AMOVA. 217 Although analysis was based on a limited number of samples, taxa-environment relationships that

218 have previously been established were observed. For instance, oligotrophs like SAR11 clade of 219 Alphaproteobacteria, SAR86, and Prochlorococcus were associated with low nutrient surface 220 water (Figure 4). Moreover, cyanobacteria were shown to be associated with the surface and DCM 221 samples. Thaumarcheaota, dominated by Nitrosopumilaceae, were strongly associated with high 222 levels of nitrite and nitrate (Figure 4).

\section{Discussion}

226 In this study we generated baseline data on the taxonomic diversity of bacteria and some archaea 227 in an exploratory survey of Benham Rise. A total of 10,599 OTUs were recovered by sequencing 228 of the 16S rRNA V4 region. By comparison, the Tara Oceans Expedition uncovered 35,000 229 prokaryotic OTUs in the euphotic zone by means of whole genome shotgun sequencing (Sunagawa 230 et al. 2015) while the GOS Expedition recovered 811 distinct ribotypes from clustering 4,125 full 
231 and partial length 16S at 97\% similarity sampling mostly from the surface layer (Rusch et al.

232 2007). It should be noted that the $515 \mathrm{~F}$ and $806 \mathrm{R}$ V4 primers used in the present study are predicted

233 to detect only about $86.8 \%$ of Bacteria and $52.9 \%$ of Archaea based on in silico evaluation using

234 SILVA TestPrime (Klindworth et al. 2013). These primers have also been shown to underrepresent

235 the SAR11 clade and some Thaumarchaeota, while overestimating Gammaproteobacteria (Apprill

236 et al. 2015; Parada et al. 2016). In addition, taxa under the candidate phyla radiation (CPR) will

237 evade detection using this V4 primer set (Brown et al. 2015).

238

239 The species richness and diversity of the microbial community in surface waters of the Benham

240 Rise is within the range of richness and diversity in adjacent surface waters of the Indian Ocean-

241 South China Sea (Zheng et al. 2016). Furthermore, the increase in microbial community richness

242 and diversity with depth is similar to findings reported in the global Tara Oceans survey. This trend

243 may be explained by an increase in the variety of ecological niches provided by marine snow

244 microenvironments (Stocker 2012; Sunagawa et al. 2015), as well as slow growth and higher

245 motility at the mesopelagic layer, which decreases predation and viral lysis (Pernthaler 2005;

246 Sunagawa et al. 2015).

247

248 Microbial community composition

249 The general composition of the microbial community in Benham Rise is similar to that described

250 from other marine environments by studies such as the GOS (Biers et al. 2009; Yooseph et al.

251 2007), Tara Oceans Expedition (Sunagawa et al. 2015), and others (DeLong et al. 2006; Yilmaz

252 et al. 2015). There is a high incidence of sequences belonging to Alphaproteobacteria,

253 Gammaproteobacteria, and Cyanobacteria (Prochlorococcus and Synechococcus) in the surface 
254 and DCM waters, and a higher frequency of archaea in the mesopelagic layer. As expected, a large

255 portion of 16S rRNA amplicons belong to the genera Synechococcus and Prochlorococcus, which

256 comprise the most abundant cyanobacteria in the global ocean and are central to primary

257 productivity and carbon cycling (Biller et al. 2015; Scanlan \& West 2002). Another taxon that is

258 similarly abundant is Alteromonas sp., which is hypothesized to be crucial for dissolved organic

259 carbon (DOC) consumption in the upper ocean layer (Pedler et al. 2014).

260

261 SAR324 (under class Deltaproteobacteria) and SAR406 (a bacterial phylum also known as Marine

262 Group A) were observed to be relatively high in DCM and UMP samples, consistent with their

263 enrichment in deep waters in both the Atlantic (Agogue et al. 2011) and the Pacific (DeLong et al.

264 2006; Pham et al. 2008). Similarly, SAR202 clade is generally associated with the aphotic zone

265 (Morris et al. 2004). The underrepresentation of SAR11 (also known as order Pelagibacterales

266 under Alphaproteobacteria) is also notable and is presumably a result of the bias in the V4 primers

267 used in this study. In the BR dataset, only $0.05 \%-1.45 \%$ of reads belonged to SAR11 whereas

$26830.9 \%$ of reads in the GOS dataset belonged to this group (Biers et al. 2009). It is estimated that

$26925 \%-50 \%$ of the microbial community in the ocean is dominated by SAR11, half of which resides

270 on the euphotic zone (Giovannoni 2017; Morris et al. 2002). Pelagibacter, a member of the SAR11

271 clade, was recently shown to assimilate dimethylsulfoniopropionate (DMSP) producing dimethyl

272 sulfide (DMS), an important compound for climate regulation (Sun et al. 2016). Another DMS-

273 producer, SAR116 (under class Alphaproteobacteria), which has been shown to be abundant in the

274 northwest Pacific Ocean (Choi et al. 2015), was detected in the BR dataset. The abundance of

275 archaea in the Benham Rise UMP corroborates the finding that archaea dominate the mesopelagic

276 layer of the Pacific Ocean (Karner et al. 2001). Of the archaeal taxa, Marine Group I and Marine 
277 Group II are the cosmopolitan groups in the ocean (Massana et al. 2000). Thaumarchaeota 278 dominates the UMP while Euryarchaeota are less abundant in the deep sea (Yilmaz et al. 2015).

279

280

Depth-related stratification of microbial community

281 Different statistical tools suggest depth-related stratification of the BR microbial community. The

282 influence of vertical stratification on microbes has also been observed by other studies (DeLong

283 et al. 2006; Hewson et al. 2006; Treusch et al. 2009). This pattern of microbial community

284 distribution is likely attributed to the differences in the physicochemical properties of the water 285 column that act as a dispersal barrier and lead to the formation of specific microbial communities 286 in different water masses (Agogue et al. 2011). The greater number of depth-specific OTUs 287 compared to the shared OTUs suggests the presence of many specialist taxa (Figure 3B). Although 288 they have a narrow utilization range, specialist taxa have high peak performance and high growth 289 rates (Mariadassou et al. 2015). These features, along with physicochemical barriers that limit 290 competition and invasion, favor resident specialist taxa, which are generally more dominant in 291 diverse habitats (Mariadassou et al. 2015).

292

293 On the other hand, the ubiquity of some bacterial clades is explained by their metabolic versatility.

294 For instance, the ubiquitous SAR324 clade displays a wide range of metabolic capabilities, 295 including lithotrophy, heterotrophy, and alkane oxidation (Sheik et al. 2014). Genomic evidence 296 for a SAR116 representative shows features of a metabolic generalist (Oh et al. 2010). SAR406 297 (also known as Marine Group A or Marinimicrobia), which has a role in the sulfur cycle, is 298 abundant in the upper ocean but is also found in oxygen minimum zones (OMZ) and anoxic basins, 299 suggesting metabolic versatility (Wright et al. 2014). 
300 Prokaryotes that are overrepresented at particular depths may have the ability to adapt to specific 301 conditions encountered at those depths (Table S5). For example, species of Spirochaeta are known

302 facultative anaerobes that can survive low oxygen levels in the UMP (Breznak \& Warnecke 2008).

303 In addition, Nitrospina species that are overrepresented in the UMP where nitrites are abundant 304 are known nitrite oxidizers (Lucker et al. 2013; Spieck et al. 2014). It is important to note, however, 305 that $16 \mathrm{~S}$ rRNA surveys are almost always incomplete. Depth specificity does not always equate to 306 the absence of that particular taxa at other depths. Differences in sampling time and small-scale 307 geographic variability might also influence the detection of certain taxa.

309 Various factors can affect microbial community structure, such as physical and chemical 310 conditions, dispersal, predation, grazing, viral lysis, resource availability, and environmental 311 variability, among others (Agogue et al. 2011; Follows \& Dutkiewicz 2011; Pedros-Alio 2006).

312 Here we examined the association of physicochemical properties of the water column with major 313 microbial phyla. CCA was able to recapitulate previously known phyla-environment associations.

314 Clades that are adapted to oligotrophic water, such as SAR11, SAR86, and Prochlorococcus, 315 clustered within the surface samples and were negatively correlated with nutrients (Figure 4). The 316 small size of Prochlorococcus cells is an adaptation to a low nutrient environment (Partensky et 317 al. 1999). SAR11, on the other hand, has a streamlined genome that allows it to thrive in low 318 nutrient environments (Giovannoni et al. 2014; Giovannoni et al. 2005). As expected for 319 oligotrophic prokaryotes (Mayali et al. 2010), SAR11 and SAR116 were also found to be 320 negatively correlated with chlorophyll-a. On the other hand, the distinct association of the archaeal

321 family, Nitrosopumilaceae, with high levels of nitrite and nitrate is consistent with their known 322 ammonia-oxidizing capabilities (Konneke et al. 2005). 


\section{Conclusions}

324

325 The diverse oceanographic regimes, rich geologic history, and biogeographic novelty of the

326 Philippine archipelago offer an excellent opportunity to examine fundamental questions on marine

327 microbial ecology and biogeography. The work presented here presents an initial glimpse into

328 marine microbial diversity in Philippine waters. By means of high-throughput sequencing of the

329 V4 region of the $16 \mathrm{~S}$ rRNA gene, we reveal that the microbial composition, richness, and diversity

330 of waters in the Benham Rise are similar to other tropical and subtropical open ocean regions.

331 Benham Rise exhibits vertical zonation of marine microbes with a greater abundance of specialist

332 taxa at different depths and increased biodiversity in the mesopelagic layer. The presence of

333 specific phyla could be correlated with physicochemical properties of the water column. Finally,

334 it is important to note the limitations of this and other community analyses that rely on

335 amplification of $16 \mathrm{~S}$ rRNA. Specifically, primer bias in the detection of certain phyla, within-

336 ribotype diversity resolution, and microbial functions cannot necessarily be inferred using a

337 targeted, single-gene approach. Further studies with more extensive sampling and that make use

338 of other broad-spectrum primers, whole metagenome sequencing, or single cell genomics will shed

339 more light on archaeal and bacterial diversity, as well as the structure and function of microbes in

340 this region of the ocean.

341

342 References

343 Agogue H, Lamy D, Neal PR, Sogin ML, and Herndl GJ. 2011. Water mass-specificity of bacterial communities in the North Atlantic revealed by massively parallel sequencing. Mol Ecol 20:258274. 10.1111/j.1365-294X.2010.04932.x

Apprill A, McNally S, Parsons R, and Weber L. 2015. Minor revision to V4 region SSU rRNA 806R gene primer greatly increases detection of SAR11 bacterioplankton. Aquatic Microbial Ecology 75:129-137. 10.3354/ame01753 
349

350

351

352

353

354

355

356

357

358

359

360

361

362

363

364

365

366

367

368

369

370

371

372

373

374

375

376

377

378

379

380

381

382

383

384

385

386

387

388

389

390

391

392

393

394

395

396

397

398

Biers EJ, Sun S, and Howard EC. 2009. Prokaryotic genomes and diversity in surface ocean waters: interrogating the global ocean sampling metagenome. Appl Environ Microbiol 75:2221-2229. 10.1128/AEM.02118-08

Biller SJ, Berube PM, Lindell D, and Chisholm SW. 2015. Prochlorococcus: the structure and function of collective diversity. Nat Rev Microbiol 13:13-27. 10.1038/nrmicro3378

Breznak JA, and Warnecke F. 2008. Spirochaeta cellobiosiphila sp. nov., a facultatively anaerobic, marine spirochaete. Int J Syst Evol Microbiol 58:2762-2768. 10.1099/ijs.0.2008/001263-0

Brown CT, Hug LA, Thomas BC, Sharon I, Castelle CJ, Singh A, Wilkins MJ, Wrighton KC, Williams $\mathrm{KH}$, and Banfield JF. 2015. Unusual biology across a group comprising more than $15 \%$ of domain Bacteria. Nature 523:208-211. 10.1038/nature14486

Caporaso JG, Lauber CL, Walters WA, Berg-Lyons D, Huntley J, Fierer N, Owens SM, Betley J, Fraser L, Bauer M, Gormley N, Gilbert JA, Smith G, and Knight R. 2012. Ultra-high-throughput microbial community analysis on the Illumina HiSeq and MiSeq platforms. ISME J 6:1621-1624. 10.1038/ismej.2012.8

Carpenter KE, and Springer VG. 2005. The center of the center of marine shore fish biodiversity: the Philippine Islands. Environmental Biology of Fishes 72:467-480. 10.1007/s10641-004-3154-4

Choi DH, Park KT, An SM, Lee K, Cho JC, Lee JH, Kim D, Jeon D, and Noh JH. 2015. Pyrosequencing revealed SAR1 16 clade as dominant dddP-containing bacteria in oligotrophic NW Pacific Ocean. PLoS One 10:e0116271. 10.1371/journal.pone.0116271

de Boer R, Peters R, Gierveld S, Schuurman T, Kooistra-Smid M, and Savelkoul P. 2010. Improved detection of microbial DNA after bead-beating before DNA isolation. Journal of Microbiological Methods 80:209-211.

DeLong EF, Preston CM, Mincer T, Rich V, Hallam SJ, Frigaard NU, Martinez A, Sullivan MB, Edwards R, Brito BR, Chisholm SW, and Karl DM. 2006. Community genomics among stratified microbial assemblages in the ocean's interior. Science 311:496-503. 10.1126/science.1120250

Dufrêne M, and Legendre P. 1997. Species assemblages and indicator species: the need for a flexible asymmetrical approach. Ecological Monographs 67:345-366.

Edgar RC, Haas BJ, Clemente JC, Quince C, and Knight R. 2011. UCHIME improves sensitivity and speed of chimera detection. Bioinformatics 27:2194-2200. 10.1093/bioinformatics/btr381

Follows MJ, and Dutkiewicz S. 2011. Modeling diverse communities of marine microbes. Ann Rev Mar Sci 3:427-451. 10.1146/annurev-marine-120709-142848

Giovannoni S, Cameron Thrash J, and Temperton B. 2014. Implications of streamlining theory for microbial ecology. ISME J 8:1553-1565. 10.1038/ismej.2014.60

Giovannoni S, Tripp HJ, Givan S, Podar M, Vergin KL, Baptista D, Bibbs L, Eads J, Richardson TH, Noordewier M, Rappé MS, Short JM, Carrington JC, and Mathur EJ. 2005. Genome Streamlining in a Cosmopolitan Oceanic Bacterium. Science 309:1242-1245.

Giovannoni SJ. 2017. SAR11 Bacteria: The Most Abundant Plankton in the Oceans. Annual Review of Marine Science 9:231-255. 10.1146/annurev-marine-010814-015934

Gordon AL, Flament P, Villanoy C, and Centurioni L. 2014. The nascent Kuroshio of Lamon Bay. $J$ Geophys Res Oceans 119:4251-4263. 10.1002/

Hewson I, Steele JA, Capone DG, and Fuhrman JA. 2006. Remarkable heterogeneity in meso- and bathypelagic bacterioplankton assemblage composition. Limnol Oceanogr 51:1274-1283.

Hu D, Wu L, Cai W, Gupta AS, Ganachaud A, Qiu B, Gordon AL, Lin X, Chen Z, Hu S, Wang G, Wang Q, Sprintall J, Qu T, Kashino Y, Wang F, and Kessler WS. 2015. Pacific western boundary currents and their roles in climate. Nature 522:299-308. 10.1038/nature14504

Huber JA, Butterfield DA, and Baross JA. 2002. Temporal Changes in Archaeal Diversity and Chemistry in a Mid-Ocean Ridge Subseafloor Habitat. Applied and Environmental Microbiology 68:15851594. 10.1128/aem.68.4.1585-1594.2002

Karner MB, DeLong EF, and Karl DM. 2001. Archaeal dominance in the mesopelagic zone of the Pacific Ocean. Nature 409:507-510.

PeerJ reviewing PDF | (2017:12:22613:1:1:NEW 13 Apr 2018) 
399

400

401

402

403

404

405

406

407

408

409

410

411

412

413

414

415

416

417

418

419

420

421

422

423

424

425

426

427

428

429

430

431

432

433

434

435

436

437

438

439

440

441

442

443

444

445

446

447

448

449

Kassen R, and Rainey PB. 2004. The ecology and genetics of microbial diversity. Annu Rev Microbiol 58:207-231. 10.1146/annurev.micro.58.030603.123654

Klindworth A, Pruesse E, Schweer T, Peplies J, Quast C, Horn M, and Glockner FO. 2013. Evaluation of general 16S ribosomal RNA gene PCR primers for classical and next-generation sequencingbased diversity studies. Nucleic Acids Res 41:e1. 10.1093/nar/gks808

Konneke M, Bernhard A, de la Torre J, Walker C, Waterbury J, and Stahl D. 2005. Isolation of an autotrophic ammonia-oxidizing marine archaeon. Nature 437:543-546.

Kozich J, Westcott S, Baxter N, Highlander S, and Schloss P. 2013. Development of a dual-index sequencing strategy and curation pipeline for analyzing amplicon sequence data on the MiSeq Illumina sequencing platform. Applied and Environmental Microbiology 79:5112-5120.

Loreau M, Naeem S, Inchausti P, Bengtsson J, Grime JP, Hector A, Hooper DU, Huston MA, Raffaelli D, Schmid B, Tilman D, and Wardle DA. 2001. Biodiversity and Ecosystem Functioning: Current Knowledge and Future Challenges. Science 294:804-808. 10.1126/science.1064088

Lucker S, Nowka B, Rattei T, Spieck E, and Daims H. 2013. The Genome of Nitrospina gracilis Illuminates the Metabolism and Evolution of the Major Marine Nitrite Oxidizer. Front Microbiol 4:27. 10.3389/fmicb.2013.00027

Mariadassou M, Pichon S, and Ebert D. 2015. Microbial ecosystems are dominated by specialist taxa. Ecol Lett 18:974-982. 10.1111/ele.12478

Massana R, DeLong EF, and Pedros-Alio C. 2000. A few cosmopolitan phylotypes dominate planktonic archaeal assemblages in widely different oceanic provinces. Appl Environ Microbiol 66:17771787.

Mayali X, Palenik B, and Burton RS. 2010. Dynamics of marine bacterial and phytoplankton populations using multiplex liquid bead array technology. Environmental Microbiology 12:975-989. 10.1111/j.1462-2920.2004.02142.x

Morris RM, Rappe MS, Connon SA, Vergin KL, Siebold WA, Carlson CA, and Giovannoni SJ. 2002. SAR11 clade dominates ocean surface bacterioplankton communities. Nature 420:806-810.

Morris RM, Rappe MS, Urbach E, Connon SA, and Giovannoni SJ. 2004. Prevalence of the ChloroflexiRelated SAR202 Bacterioplankton Cluster throughout the Mesopelagic Zone and Deep Ocean. Applied and Environmental Microbiology 70:2836-2842. 10.1128/aem.70.5.2836-2842.2004

Oh HM, Kwon KK, Kang I, Kang SG, Lee JH, Kim SJ, and Cho JC. 2010. Complete genome sequence of "Candidatus Puniceispirillum marinum" IMCC1322, a representative of the SAR116 clade in the Alphaproteobacteria. J Bacteriol 192:3240-3241. 10.1128/JB.00347-10

Parada AE, Needham DM, and Fuhrman JA. 2016. Every base matters: assessing small subunit rRNA primers for marine microbiomes with mock communities, time series and global field samples. Environmental Microbiology 18:1403-1414. 10.1111/1462-2920.13023

Partensky F, Hess WR, and D. Vaulot D. 1999. Prochlorococcus, a arine Photosynthetic Prokaryote of Global Significance. Microbiol Mol Biol Rev 63:106-127.

Parthasarathy H, Hill E, and MacCallum C. 2007. Global ocean sampling collection. PLoS Biol 5:e83. 10.1371/journal.pbio.0050083

Pedler BE, Aluwihare LI, and Azam F. 2014. Single bacterial strain capable of significant contribution to carbon cycling in the surface ocean. Proc Natl Acad Sci U S A 111:7202-7207. 10.1073/pnas. 1401887111

Pedros-Alio C. 2006. Marine microbial diversity: can it be determined? Trends Microbiol 14:257-263. 10.1016/j.tim.2006.04.007

Pernthaler J. 2005. Predation on prokaryotes in the water column and its ecological implications. Nat Rev Micro 3:537-546.

Pham VD, Konstantinidis KT, Palden T, and DeLong EF. 2008. Phylogenetic analyses of ribosomal DNA-containing bacterioplankton genome fragments from a $4000 \mathrm{~m}$ vertical profile in the North Pacific Subtropical Gyre. Environ Microbiol 10:2313-2330. 10.1111/j.1462-2920.2008.01657.x

Philippines. 2009. A partial submission of data and information on the outer limits of the continental shelf of the Republic of the Philippines pursuant to article 76 (8) of the United Nations Convention on 
450

451

452

453

454

455

456

457

458

459

460

461

462

463

464

465

466

467

468

469

470

471

472

473

474

475

476

477

478

479

480

481

482

483

484

485

486

487

488

489

490

491

492

493

494

495

496

497

498

499

500

the Law of the Sea. Available at

http://www.un.org/depts/los/clcs_new/submissions_files/submission_phl_22_2009.htm.

Quast C, Pruesse E, Yilmaz P, Gerken J, Schweer T, Yarza P, Peplies J, and Glöckner FO. 2013. The SILVA ribosomal RNA gene database project: improved data processing and web-based tools. Nucleic Acids Research 41:D590-D596. 10.1093/nar/gks1219

Ramette A. 2007. Multivariate analyses in microbial ecology. FEMS Microbiol Ecol 62:142-160. 10.1111/j.1574-6941.2007.00375.x

Rusch DB, Halpern AL, Sutton G, Heidelberg KB, Williamson S, Yooseph S, Wu D, Eisen JA, Hoffman JM, Remington K, Beeson K, Tran B, Smith H, Baden-Tillson H, Stewart C, Thorpe J, Freeman J, Andrews-Pfannkoch C, Venter JE, Li K, Kravitz S, Heidelberg JF, Utterback T, Rogers YH, Falcon LI, Souza V, Bonilla-Rosso G, Eguiarte LE, Karl DM, Sathyendranath S, Platt T, Bermingham E, Gallardo V, Tamayo-Castillo G, Ferrari MR, Strausberg RL, Nealson K, Friedman R, Frazier M, and Venter JC. 2007. The Sorcerer II Global Ocean Sampling expedition: northwest Atlantic through eastern tropical Pacific. PLoS Biol 5:e77.

10.1371/journal.pbio.0050077

Sanciangco JC, Carpenter KE, Etnoyer PJ, and Moretzsohn F. 2013. Habitat availability and heterogeneity and the indo-pacific warm pool as predictors of marine species richness in the tropical Indo-Pacific. PLoS One 8:e56245. 10.1371/journal.pone.0056245

Savov IP. 2005. Petrology and Geochemistry of West Philippine Basin Basalts and Early Palau-Kyushu Arc Volcanic Clasts from ODP Leg 195, Site 1201D: Implications for the Early History of the Izu-Bonin-Mariana Arc. Journal of Petrology 47:277-299. 10.1093/petrology/egi075

Scanlan DJ, and West NJ. 2002. Molecular ecology of the marine cyanobacterial genera Prochlorococcus and Synechococcus. FEMS Microbiol Ecol 40:1-12. 10.1111/j.1574-6941.2002.tb00930.x

Schloss PD. 2008. Evaluating different approaches that test whether microbial communities have the same structure. ISME J 2:265-275. 10.1038/ismej.2008.5

Schloss PD, Girard RA, Martin T, Edwards J, and Thrash JC. 2016. Status of the Archaeal and Bacterial Census: an Update. MBio 7. 10.1128/mBio.00201-16

Schloss PD, Westcott SL, Ryabin T, Hall JR, Hartmann M, Hollister EB, Lesniewski RA, Oakley BB, Parks DH, Robinson CJ, Sahl JW, Stres B, Thallinger GG, Van Horn DJ, and Weber CF. 2009. Introducing mothur: Open-Source, Platform-Independent, Community-Supported Software for Describing and Comparing Microbial Communities. Applied and Environmental Microbiology 75:7537-7541. 10.1128/aem.01541-09

Segata N, Izard J, Waldron L, Gevers D, Miropolsky L, Garrett W, and Huttenhower C. 2011. Metagenomic biomarker discovery and explanation. Genome Biol 12.

Sheik CS, Jain S, and Dick GJ. 2014. Metabolic flexibility of enigmatic SAR324 revealed through metagenomics and metatranscriptomics. Environ Microbiol 16:304-317. 10.1111/14622920.12165

Spieck E, Keuter S, Wenzel T, Bock E, and Ludwig W. 2014. Characterization of a new marine nitrite oxidizing bacterium, Nitrospina watsonii sp. nov., a member of the newly proposed phylum "Nitrospinae". Syst Appl Microbiol 37:170-176. 10.1016/j.syapm.2013.12.005

Staley JT. 2006. The bacterial species dilemma and the genomic-phylogenetic species concept. Philos Trans R Soc Lond B Biol Sci 361:1899-1909. 10.1098/rstb.2006.1914

Stocker R. 2012. Marine Microbes See a Sea of Gradients. Science 338:628-633. 10.1126/science. 1208929

Strickland J, and Parsons T. 1972. A Practical Handbook of Seawater Analysis: Fishery Research Board, Canada.

Sun J, Todd JD, Thrash JC, Qian Y, Qian MC, Temperton B, Guo J, Fowler EK, Aldrich JT, Nicora CD, Lipton MS, Smith RD, De Leenheer P, Payne SH, Johnston AWB, Davie-Martin CL, Halsey KH, and Giovannoni SJ. 2016. The abundant marine bacterium Pelagibacter simultaneously catabolizes dimethylsulfoniopropionate to the gases dimethyl sulfide and methanethiol. Nature Microbiology:16065. 10.1038/nmicrobiol.2016.65

PeerJ reviewing PDF | (2017:12:22613:1:1:NEW 13 Apr 2018) 
501

502

503

504

505

506

507

508

509

510

511

512

513

514

515

516

517

518

519

520

521

522

523

524

525

526

527

528

529

530

531

532

533

534

Sunagawa S, Coelho LP, Chaffron S, Kultima JR, Labadie K, Salazar G, Djahanschiri B, Zeller G, Mende DR, Alberti A, Cornejo-Castillo FM, Costea PI, Cruaud C, d'Ovidio F, Engelen S, Ferrera I, Gasol JM, Guidi L, Hildebrand F, Kokoszka F, Lepoivre C, Lima-Mendez G, Poulain J, Poulos BT, Royo-Llonch M, Sarmento H, Vieira-Silva S, Dimier C, Picheral M, Searson S, KandelsLewis S, coordinators TO, Bowler C, de Vargas C, Gorsky G, Grimsley N, Hingamp P, Iudicone D, Jaillon O, Not F, Ogata H, Pesant S, Speich S, Stemmann L, Sullivan MB, Weissenbach J, Wincker P, Karsenti E, Raes J, Acinas SG, and Bork P. 2015. Structure and function of the global ocean microbiome. Science 348. 10.1126/science.1261359

Ter Braak CJF. 1986. Canonical Correspondence Analysis: A New Eigenvector Technique for Multivariate Direct Gradient Analysis. Ecology 67:1167-1179. 10.2307/1938672

Tittensor DP, Mora C, Jetz W, Lotze HK, Ricard D, Berghe EV, and Worm B. 2010. Global patterns and predictors of marine biodiversity across taxa. Nature 466:1098-1101. 10.1038/nature09329

Treusch AH, Vergin KL, Finlay LA, Donatz MG, Burton RM, Carlson CA, and Giovannoni SJ. 2009. Seasonality and vertical structure of microbial communities in an ocean gyre. ISME J 3:11481163. 10.1038/ismej.2009.60

Wright JJ, Mewis K, Hanson NW, Konwar KM, Maas KR, and Hallam SJ. 2014. Genomic properties of Marine Group A bacteria indicate a role in the marine sulfur cycle. ISME J 8:455-468. 10.1038/ismej.2013.152

Yilmaz P, Yarza P, Rapp JZ, and Glockner FO. 2015. Expanding the World of Marine Bacterial and Archaeal Clades. Front Microbiol 6:1524. 10.3389/fmicb.2015.01524

Yooseph S, Sutton G, Rusch DB, Halpern AL, Williamson SJ, Remington K, Eisen JA, Heidelberg KB, Manning G, Li W, Jaroszewski L, Cieplak P, Miller CS, Li H, Mashiyama ST, Joachimiak MP, van Belle C, Chandonia JM, Soergel DA, Zhai Y, Natarajan K, Lee S, Raphael BJ, Bafna V, Friedman R, Brenner SE, Godzik A, Eisenberg D, Dixon JE, Taylor SS, Strausberg RL, Frazier M, and Venter JC. 2007. The Sorcerer II Global Ocean Sampling expedition: expanding the universe of protein families. PLoS Biol 5:e16. 10.1371/journal.pbio.0050016

Zheng X, Dai X, and Huang L. 2016. Spatial Variations of Prokaryotic Communities in Surface Water from India Ocean to Chinese Marginal Seas and their Underlining Environmental Determinants. Frontiers in Marine Science 3. 10.3389/fmars.2016.00017

\section{Acknowledgements}

The authors would like to thank the Bureau of Fisheries and Aquatic Resources of the Philippines,

specifically the crew and staff of the MV DA-BFAR vessel. The authors would also like to acknowledge Grieg F. Steward for his valuable comments and suggestions. 


\section{Figure 1}

Benham Rise, Philippines

Benham Rise is an underwater plateau located northeast of the Philippines. Physicochemical parameters were measured at 24 stations (blue dots) while water samples for microbial community analysis were collected from various depths at 5 stations (red dots). Stations are plotted in Ocean Data View (Schlitzer, R., Ocean Data View, https://odv.awi.de, 2018)
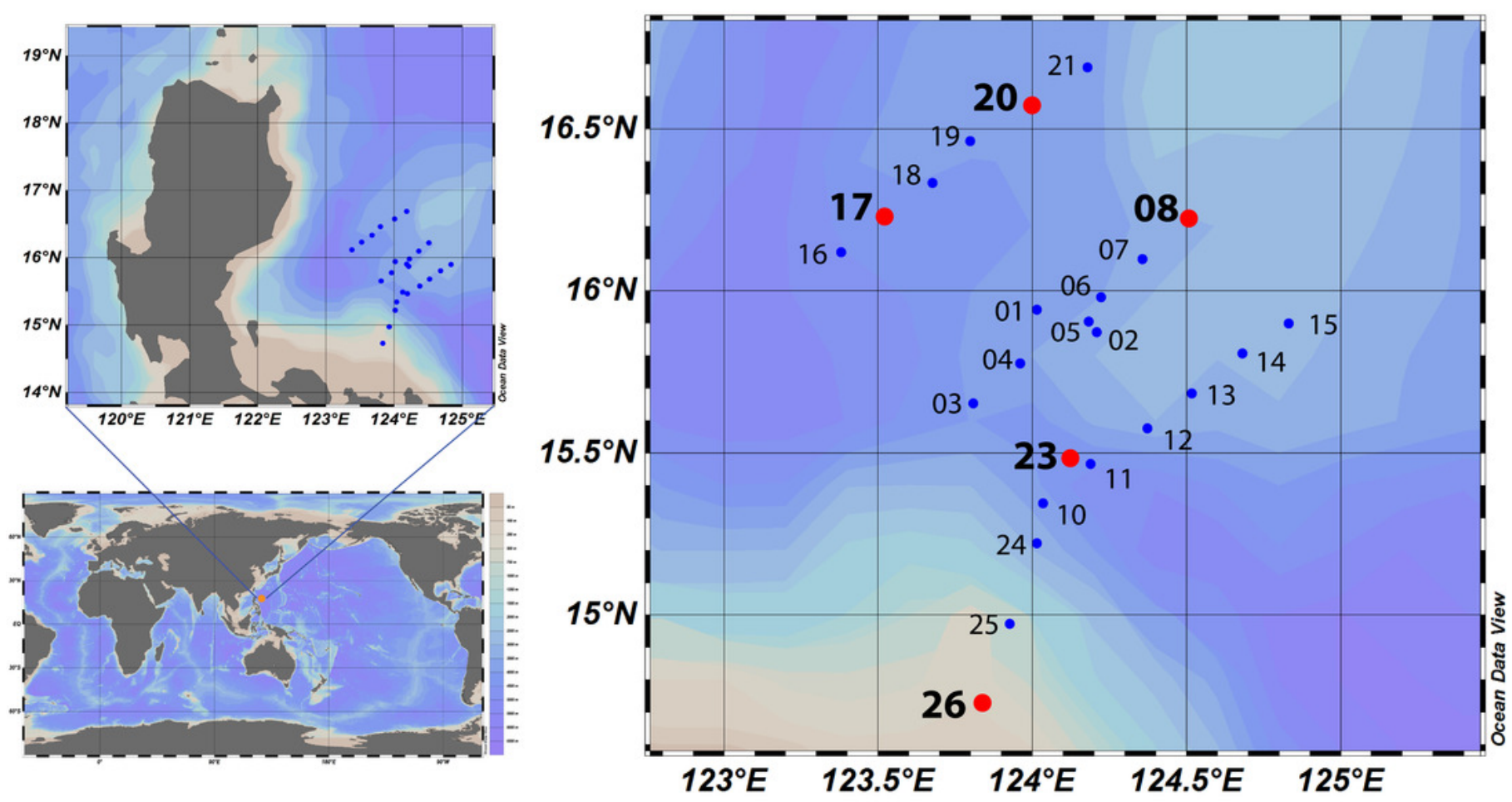


\section{Figure 2 (on next page)}

Depth-related patterns in microbial richness and diversity

(A) Species richness, as estimated using the Chao index, and (B) diversity, based on the Shannon index, increase with depth. 


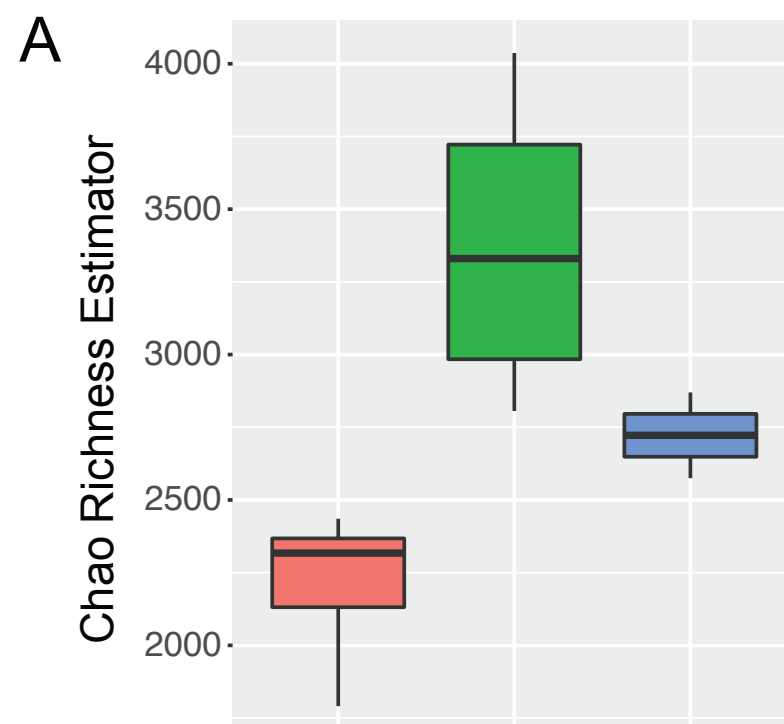

B

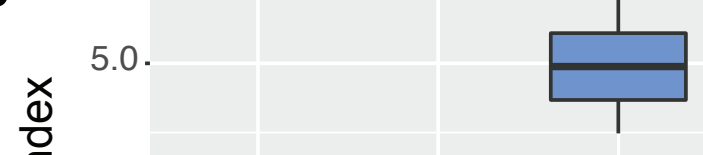

Depth ESURF $\boxminus \mathrm{DCM}$ 曰UMP 


\section{Figure 3 (on next page)}

Microbial community composition and structure in the Benham Rise water column

(A) Samples from the same depth taken at different stations exhibit more similar community composition (SURF, surface, DCM, deep chlorophyll maximum, UMP, upper mesopelagic). Heatmap represents the Jaccard dissimilarity index between samples with dark orange signifying high similarity. (B) Number of OTUs that are shared among the three depths or that are unique to specific depths. (C) Relative abundance of microbial phyla at three depths. For simplicity, less abundant groups were classified under "other phyla." 

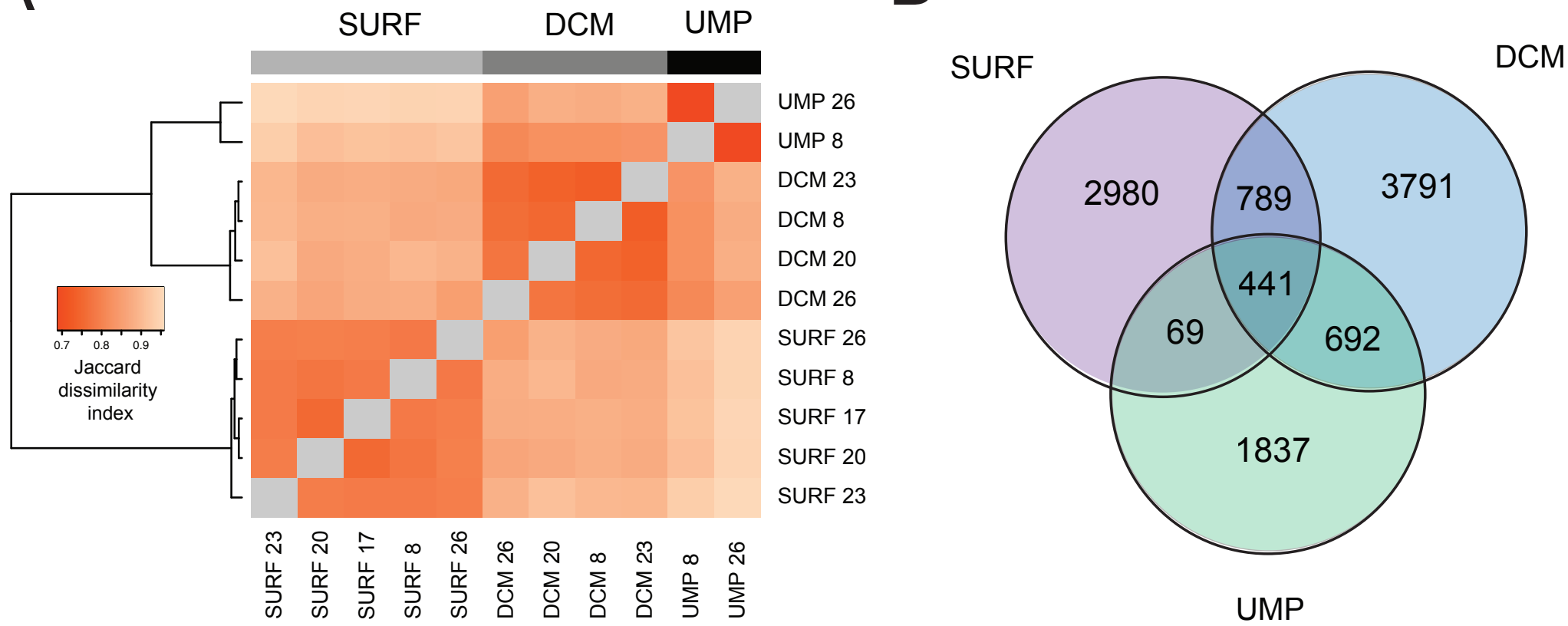

C

UMP 26

UMP 8

DCM 23

DCM 8

DCM 20

DCM 26

SURF 26

SURF 8

SURF 17

SURF 20

SURF 23

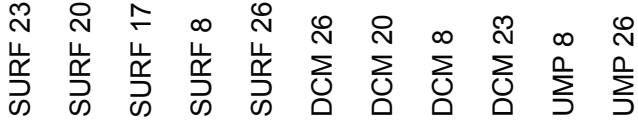

UMP

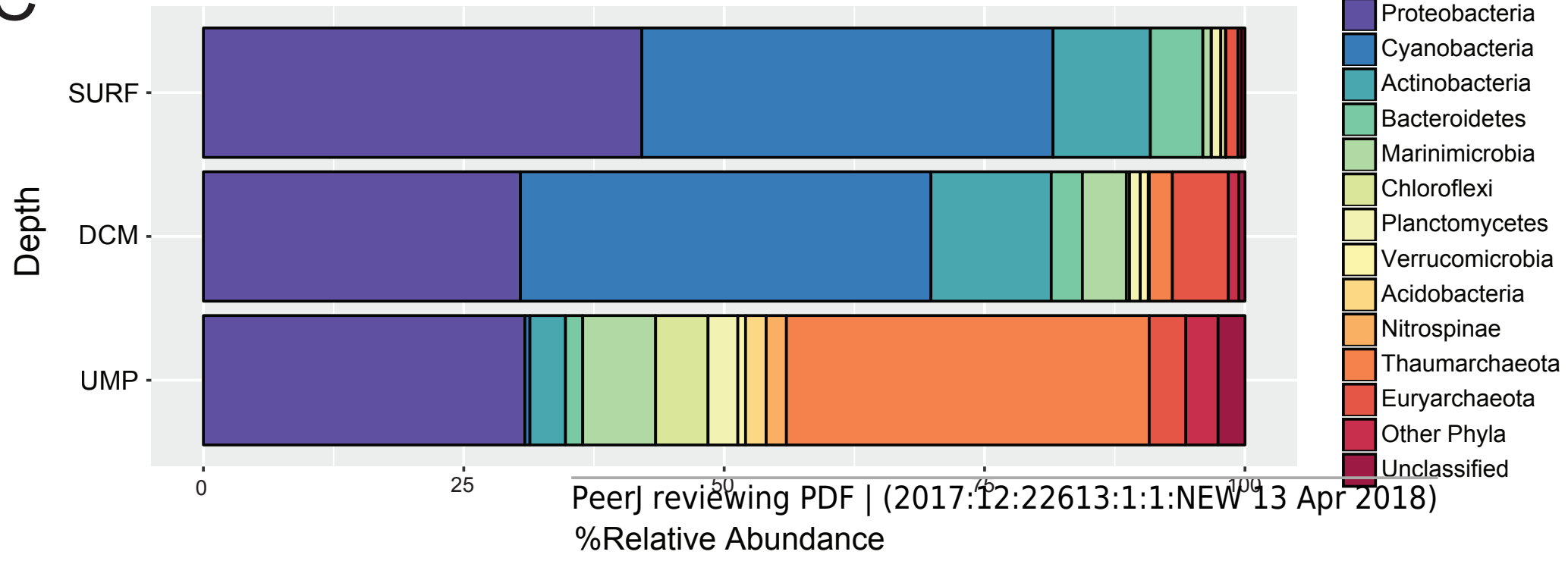




\section{Figure 4 (on next page)}

Canonical correspondence analysis (CCA) ordination plot

The relationship between sampling sites and depths (green), microbial taxa (black), and specific environmental parameters (red arrows) are shown. The combination of the environmental variables explained $86.71 \%$ of the total variance in the relative abundance of selected major taxa in Benham Rise. 


\section{(axes F1 and F2: 86.71\%)}

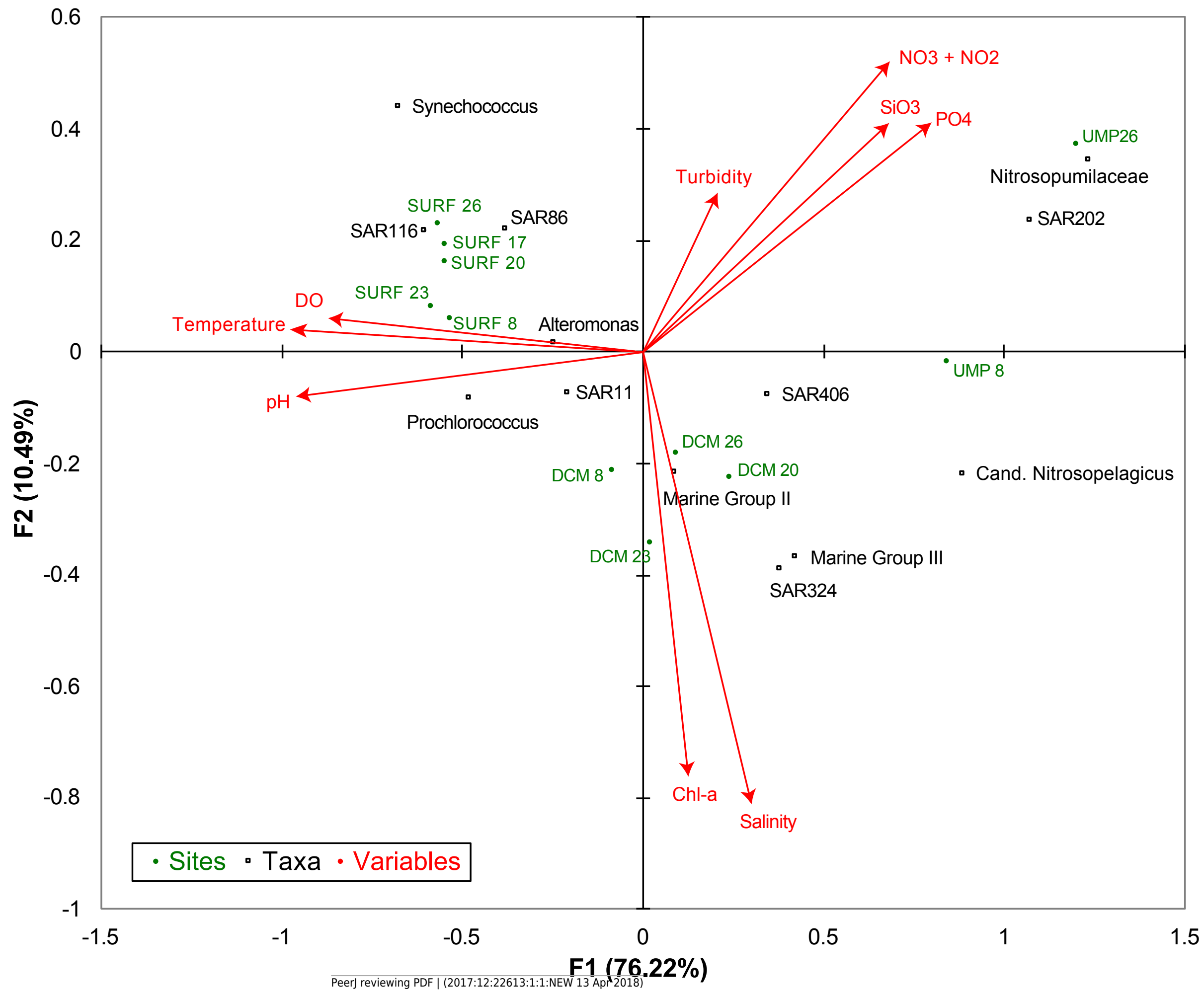

